\title{
Gestão da segurança e saúde no trabalho em empresas produtoras de baterias automotivas: um estudo para identificar boas práticas
}

\author{
Otávio José de Oliveira ${ }^{a, *}$, Alessandra Bizan de Oliveira ${ }^{\mathrm{b}}$, \\ Renan Augusto de Almeida ${ }^{\mathrm{c}}$ \\ a,*otavio@feb.unesp.br, UNESP, Brasil \\ balebizan@terra.com.br, UNESP, Brasil \\ crenan_aa@feb.unesp.br, UNESP, Brasil
}

\begin{abstract}
Resumo
A gestão da Segurança e Saúde no Trabalho (SST) reduz riscos de acidentes, promove a saúde e a satisfação dos trabalhadores, melhora os resultados operacionais e a imagem das organizações, sobretudo daquelas do setor industrial. Este artigo tem como principal objetivo identificar, a partir do método de estudo de caso duplo, boas práticas e principais dificuldades relacionadas à gestão da SST em empresas fabricantes de baterias automotivas da região centro-oeste do Estado de São Paulo. A coleta de dados se deu por meio de observação in loco, análise de documentos e entrevistas semiestruturadas com gestores e colaboradores. 0 trabalho revelou que o apoio da alta direção e da área de Recursos Humanos e a participação ativa dos colaboradores são determinantes para o sucesso deste sistema e que as principais dificuldades na sua gestão advêm de falhas na comunicação, inexistência de indicadores de SST e ausência de visão estratégica para segurança.
\end{abstract}

Palavras-chave

Segurança e saúde do trabalho. Sistemas de gestão. Baterias automotivas. Práticas de gestão.

\section{Introdução}

A globalização dos mercados tem aumentado consideravelmente a competitividade mundial, o que impõe às organizações a contínua busca por novas ferramentas de gestão que possam auxiliar na melhoria de seus processos.

Com a implantação de sistemas de gestão específicos (qualidade, meio ambiente, segurança e saúde do trabalho, responsabilidade social, etc.), as organizações objetivam o aumento da qualidade de produtos e serviços, o desenvolvimento sustentável, melhor relacionamento com a sociedade e, consequentemente, o aumento da lucratividade, podendo, assim, transformar as pressões de mercado em vantagens competitivas.

Neste contexto, o bom desempenho em Segurança e Saúde no Trabalho (SST) é decisivo para as empresas, uma vez que este sistema reduz os riscos de acidentes, promove a saúde e a satisfação dos trabalhadores, melhora os resultados operacionais e a imagem da organização, criando novas oportunidades de crescimento.

A SST ganha importância ainda mais acentuada quando se considera o ambiente de produção de baterias automotivas em função das peculiaridades de seu processo produtivo e da intensa utilização de insumos, além da geração de resíduos altamente nocivos à saúde humana.

A questão de pesquisa que norteou o desenvolvimento deste trabalho foi: quais práticas gerenciais podem ser adotadas pelas empresas produtoras de baterias automotivas para melhorar as características do seu ambiente de trabalho e minimizar os riscos e a ocorrência de acidentes e doenças ocupacionais?

Este artigo tem como principal objetivo identificar boas práticas e principais dificuldades relacionadas à gestão da SST em duas empresas fabricantes de baterias automotivas localizadas na região centro-oeste do Estado de São Paulo. 
Para garantir seu foco, procurou-se delimitar o escopo desta pesquisa em relação aos seguintes elementos: objeto de estudo (Sistemas de Gestão da Segurança e Saúde no Trabalho), recorte geográfico (centro-oeste paulista) e segmento de atuação das empresas (setor de baterias automotivas).

A seguir, é apresentada uma breve revisão bibliográfica acerca de Sistemas de Gestão da Segurança e Saúde no Trabalho (SGSST) e das dificuldades e recomendações para gestão da SST. Na sequência, é apresentado o método de pesquisa utilizado no trabalho, seguido da apresentação e análise de dois estudos de caso em empresas produtoras de baterias automotivas. Por fim, são apresentadas, de forma genérica e sistematizada, boas práticas para gestão da SST em empresas deste tipo.

\section{Sistemas de gestão da segurança e saúde no trabalho}

Um sistema de gestão é um conjunto de elementos inter-relacionados utilizados para estabelecer, executar e alcançar políticas e objetivos de diversas ordens, a partir de atividades de planejamento, responsabilidades, práticas, procedimentos, processos e recursos (OHSAS, 2007).

Segundo a - Occupational Health and Safety Assessment Series (OHSAS, 2007), SST são condições e fatores que afetam - ou poderiam afetar - a segurança e a saúde de funcionários ou de outros trabalhadores (incluindo trabalhadores temporários e terceirizados), visitantes ou qualquer outra pessoa no local de trabalho.

Para Lin e Mills (2001), os principais fatores que influenciam a segurança são o desempenho da organização, o tamanho da companhia, a gestão e o compromisso dos funcionários quanto à SST.

Um SGSST pode ser definido como parte do sistema de gestão maior de uma organização utilizada para desenvolver e implantar sua política e gerenciar seus riscos de SST (OHSAS, 2007).

De acordo com Salamone (2008), as motivações que levam as empresas a adotarem SGSSTs se devem, principalmente, a fatores como melhoria contínua, melhoria na imagem, aumento da competitividade, chance de reduzir os custos com gestão, novas oportunidades de mercado, produtividade mais alta e melhorias nos produtos.

A implantação de SGSSTs tem sido a principal estratégia das empresas para minimizar o sério problema social e econômico dos acidentes e das doenças relacionadas ao trabalho, sendo, ainda, um importante fator para o aumento de sua competitividade (TRIVELATO, 2002).
Quando um funcionário é admitido, a percepção que ele tiver do ambiente físico e social encontrado o influenciará no seu comportamento cotidiano. Por isso, são de suma importância determinados aspectos, como ordem, limpeza e asseio pessoal, bem como a própria organização e a utilização dos espaços por meio de um layout adequado (BARBOSA FILHO, 2001). 0 sucesso de um SGSST é dependente da sua natureza de intervenção, das características do local de trabalho e das características do ambiente externo (ROBSON et al., 2007).

Neste sentido, os SGSSTs são ferramentas gerenciais que contribuem para a eficiente melhoria do desempenho das empresas com relação às questões de segurança e saúde, visando atendimento às legislações, aumento da produtividade, diminuição de acidentes, credibilidade perante a opinião pública e crescente conscientização quanto à segurança e à saúde dos colaboradores e parceiros da organização.

0 princípio básico de um SGSST baseado em aspectos normativos envolve a necessidade de se determinarem parâmetros de avaliação que incorporem não só os aspectos operacionais, mas também a política, o gerenciamento e o comprometimento da alta direção com o processo, bem como a mudança e a melhoria contínua das condições de segurança e saúde no trabalho (QUELHAS; ALVES; FILARD0, 2003).

A norma britânica BS 8800 (Guide to Occupational Health and Safety Systems), criada em 1996, foi a primeira tentativa bem sucedida de se estabelecer uma referência normativa para a implementação de SGSST.

Em 1999, foi publicada pela British Standards Instituion (BSI) a norma OHSAS 18001, que foi formulada por um grupo de entidades internacionais (BVQ1, DNV, LOYDS, SGS e outras), que se fundamentaram na BS 8800. Ela foi desenvolvida em resposta às necessidades das empresas em gerenciar suas obrigações de SST de maneira mais eficiente.

É importante destacar que, em julho de 2007, a norma OHSAS 18001, 1999 foi substituída pela OHSAS 18001, 2007 e algumas alterações foram feitas, tal como a introdução de novas exigências e novos requisitos para a investigação de acidentes, refletindo, assim, a experiência de dezesseis mil organizações certificadas em mais de oitenta países (QSP, 2007).

A OHSAS 18001 tem como objetivo fornecer às organizações os elementos de um SGSST eficaz, que possa auxiliá-las a alcançar seus objetivos de segurança e saúde do trabalho (OHSAS 18001, 2007). Os requisitos da OHSAS 18001 são apresentados no Quadro 1. 
Esta norma é aplicável a todos os tipos e portes de organizações e passível de integração com outros sistemas de gestão (qualidade, meio ambiente e responsabilidade social). Ela não define padrões de desempenho ou indica como podem ser desenvolvidos seus elementos, apenas apresenta requisitos básicos a serem cumpridos. Essa condição pode resultar em empresas com sistemas de gestão de SST baseados na OHSAS, porém com resultados de desempenho completamente diferentes.

Conforme mostra a Figura 1, a norma OHSAS é baseada na metodologia PDCA (plan, do, check e act) (OHSAS, 2007).

\section{Dificuldades e recomendações para gestão da segurança e saúde no trabalho}

As organizações estão enfrentando um ambiente repleto de mudanças e complexidades que interferem profundamente no desempenho da produção, no ciclo de vida dos produtos e na velocidade de modernização de produtos e processos (KOUFTEROS; VONDEREMBSE; DOLL, 2002).

A internacionalização dos mercados tem aumentado a competitividade entre as empresas, o que as tem conduzido a se empenharem em projetos que possam aumentar suas chances de sobrevivência, tal como o desenvolvimento de sistemas de gestão normatizados. Porém, para alcançar bons resultados, estes projetos precisam ser adequadamente planejados, organizados, monitorados, controlados e avaliados (RAYMOND; BERGERON, 2008).

Ao longo da década de 80 , século XX, o conceito de cultura organizacional ganhou grande destaque entre pesquisadores e executivos. Nessa época, anunciava-se que a chave para o sucesso das organizações era o desenvolvimento de uma cultura corporativa forte e única, acrescentando-se que a alta direção deveria construí-la por meio da articulação de um conjunto de valores, que seriam reforçados por políticas formais e informais; essa cultura corporativa deveria também ser partilhada e respeitada por todos os colaboradores (MILAN; PRETTO; PIGOZZI, 2005).

Dessa forma, a cultura corporativa tornou-se rapidamente uma arma a favor dos negócios bem sucedidos. Muitas organizações têm mostrado um interesse crescente no conceito da cultura de segurança como um meio de reduzir os riscos de acidentes e incidentes.

A segurança não deve somente ser avaliada por meio de regulamentações, mas sim se tornar parte da cultura da organização pelo comprometimento de todos os níveis da administração (MOHAMED, 2002). Estudos mostram que o sucesso na implantação de um SGSST depende da habilidade dos agentes responsáveis pelas mudanças em controlar situações complexas e imprevisíveis (HASLE; JENSEN, 2006).

Quadro 1. Requisitos da OHSAS 18001.

\begin{tabular}{|c|}
\hline 4.1 Requisitos gerais \\
\hline 4.2 Política de SST \\
\hline 4.3 Planejamento \\
\hline $\begin{array}{l}\text { 4.3.1 Identificação de perigos, avaliação de riscos e } \\
\text { determinação de controles }\end{array}$ \\
\hline 4.3.2 Requisitos legais e outros \\
\hline 4.3.3 Objetivos e programa(s) \\
\hline 4.3.4 Programa de gestão de SST \\
\hline 4.4 Implementação e operação \\
\hline $\begin{array}{l}\text { 4.4.1 Recursos, funções, responsabilidades, prestações } \\
\text { de contas e autoridades }\end{array}$ \\
\hline 4.4.2 Competência, treinamento e conscientização \\
\hline 4.4.3 Comunicação, participação e consulta \\
\hline 4.4.4 Documentação \\
\hline 4.4.5 Controle de documentos \\
\hline 4.4.6 Controle operacional \\
\hline 4.4.7 Preparação e resposta a emergências \\
\hline 4.5 Verificação \\
\hline 4.5.1 Monitoramento e medição do desempenho \\
\hline $\begin{array}{l}\text { 4.5.2 Avaliação do atendimento a requisitos legais e } \\
\text { outros }\end{array}$ \\
\hline $\begin{array}{l}\text { 4.5.3 Investigação de incidentes, não conformidade, } \\
\text { ação corretiva e ação preventiva }\end{array}$ \\
\hline 4.5.3.1 Investigação de incidente \\
\hline $\begin{array}{l}\text { 4.5.3.2 Não conformidade, ação corretiva e } \\
\text { ação preventiva }\end{array}$ \\
\hline 4.5.4 Controle de registros \\
\hline 4.5.5 Auditoria interna \\
\hline 4.6 Análise crítica pela direção \\
\hline
\end{tabular}

Fonte: OHSAS (2007).

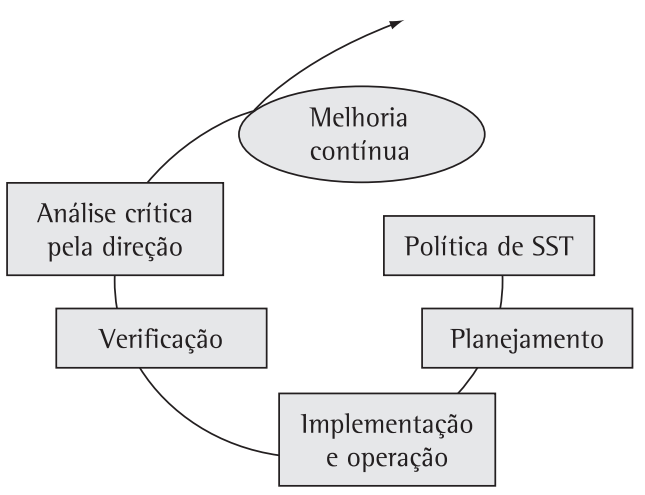

Figura 1. Espiral do sistema de segurança e saúde no trabalho. Fonte: OHSAS (2007). 
Beer e Nohria (2001) salientam que a maioria dos casos de insucesso de SGSSTs está na pressa de mudar a empresa. Os gestores confundem-se em suas iniciativas e perdem o foco com a quantidade de alternativas disponíveis na literatura e/ou propostas de consultores.

Os funcionários se tornam mais dispostos a cooperar com os projetos propostos pela organização quando começam a acreditar no real comprometimento da direção (LANGFORD ROWLINSON; SAWACHA, 2000). É esta participação em conjunto, direção-colaboradores, que proporciona o sentimento de responsabilidade coletiva, tornando-se fator decisivo para o sucesso da mudança (CHOUDHRY; FANG; MOHAMED, 2007).

A aceitação e o entendimento do conceito de SST por parte da diretoria e a participação da área de recursos humanos neste processo de mudança são de fundamental importância para que se consiga o envolvimento de todos os colaboradores e a obtenção de bons resultados no projeto. As organizações podem melhorar os resultados em segurança focando em melhorias de equipamentos e procedimentos, e procurando mudar positivamente o comportamento humano por meio da educação e do treinamento (MOHAMED, 2002).

0 comprometimento da alta direção e a participação efetiva dos colaboradores na criação de uma cultura de segurança consistente faz com que todos se sintam mais responsáveis quanto à prevenção e à manutenção de um ambiente livre de acidentes e riscos à saúde (CHOUDHRY; FANG; MOHAMED, 2007).

Portanto, o sucesso de um programa de SST está intimamente vinculado à participação da alta direção, da média gerência e dos colaboradores na elaboração de políticas e no estabelecimento de um sistema de avaliação que leve à melhoria contínua (ABUDAYYEH et al., 2006). Há uma correlação direta entre um ambiente de trabalho seguro e o clima de segurança, que incluem compromisso da administração, comunicação, envolvimento de colaboradores e atitudes proativas (MOHAMED, 2002).

A eficiência de SGSSTs poderia ser consideravelmente maior se fossem previamente observados alguns fatores negativos e de ocorrência comum, como: perfil inadequado e falta de experiência dos empresários nestes assuntos; indicadores de desempenho focados apenas em aspectos financeiros; falta de constância de propósito; alegação de falta de tempo para realizar algumas tarefas de implantação de SGSST; dificuldade de estabelecer metas e planos estratégicos a longo prazo; falta de sentimento dos funcionários como efetivos colaboradores para o crescimento da empresa; documentos mais burocráticos do que o necessário; alta rotatividade da força de trabalho, e pouca utilização de registros (ANHALON; ZOQUI; PINTO, 2005).

Segundo Aggelogiannopoulo, Drosinos, Athanasopoulos, (2007), a falta de experiência e conhecimento dos colaboradores acerca do novo sistema a ser implantado é um importante obstáculo a ser superado. 0 inadequado fluxo das informações técnicas, de legislações e requisitos aplicáveis ao negócio da empresa, e a falta de divulgação dos resultados de desempenho são fatores limitantes para que o processo de implantação de SGSSTs alcance bons resultados.

Para Shi et al. (2008), o treinamento técnico para funcionários do chão-de-fábrica é um fator importante para que se consiga contribuir com o desenvolvimento e a manutenção de um sistema de gestão.

Em pesquisa realizada por Salomone (2008), constataram-se os seguintes obstáculos na implantação de SGSSTs: custos altos, dificuldades em encontrar recursos humanos competentes, escassez de informações, falta de transparência das normas, insuficiente apoio financeiro e dificuldade em mudar a mentalidade e a cultura das pessoas envolvidas no processo.

No Quadro 2, figuram, de forma sumária, as principais motivações e os obstáculos encontrados na implantação de SGSSTs, baseados na norma OHSAS 18001 (SALOMONE, 2008).

Quadro 2. Principais motivações e obstáculos na implantação de SGSSTs.

\begin{tabular}{|c|c|}
\hline Motivações & Obstáculos \\
\hline Melhoria contínua & $\begin{array}{c}\text { Dificuldades no } \\
\text { gerenciamento }\end{array}$ \\
\hline Melhoria na imagem & Custo muito alto \\
\hline Maior competitividade & $\begin{array}{c}\text { Falta de recursos } \\
\text { humanos competentes }\end{array}$ \\
\hline Diminuição dos custos & Falta de informação \\
\hline $\begin{array}{c}\text { Novas oportunidades } \\
\text { no mercado }\end{array}$ & $\begin{array}{c}\text { Falta de clareza } \\
\text { de padrões }\end{array}$ \\
\hline $\begin{array}{c}\text { Melhoria na } \\
\text { produtividade }\end{array}$ & $\begin{array}{c}\text { Falta de recursos } \\
\text { financeiros }\end{array}$ \\
\hline Melhorias no produto & \\
\hline Pressões governamentais & \\
\hline Pressão da & \\
\hline comunidade local & Pressão dos clientes \\
\hline
\end{tabular}

Fonte: Adaptado de Salomone (2008). 


\section{Método de pesquisa}

A realização deste trabalho se deu por meio de uma pesquisa qualitativa, com base na metodologia de estudo de caso duplo.

Segundo Santos, Rossi, Jardilino, (2000), a pesquisa qualitativa se preocupa fundamentalmente com a compreensão e a interpretação do fenômeno estudado, tendo como principal objetivo compreendê-lo, explorá-lo e especificá-lo.

A realização de estudos de caso múltiplos, conforme ressalta Yin (2003), pode trazer consideráveis contribuições à teoria vigente ou mesmo modificá-la. Configura-se desta forma o objetivo do estudo dos dois casos apresentados neste trabalho: contribuir com a teoria e auxiliar um setor produtivo específico (baterias automotivas) a partir da sistematização de procedimentos (boas práticas).

Os instrumentos de coleta de dados foram entrevistas semiestruturadas com os técnicos de segurança, gerentes de produção e alguns funcionários-chave do chão-de-fábrica. Também foram realizadas observações in loco, por meio de quatro visitas a cada unidade fabril estudada no ano de 2008, e análise de documentos, principalmente os referentes aos procedimentos e às instruções de trabalho relacionados à SST.

A Figura 2 apresenta a sistematização dos procedimentos metodológicos utilizados nesta pesquisa.

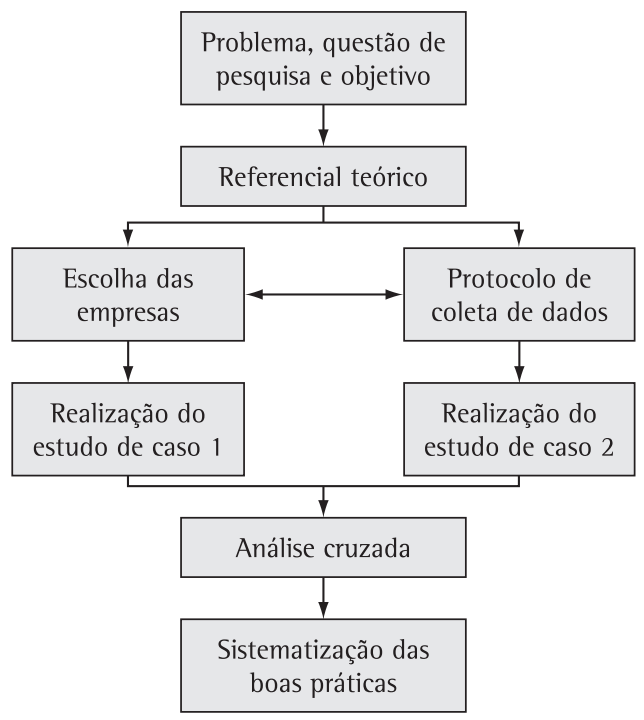

Figura 2. Procedimentos metodológicos da pesquisa.

\section{Estudos de caso}

Para esta pesquisa, foram realizados dois estudos de caso com função exploratória, que tiveram como objetivo melhor embasar os pesquisadores e contribuir com a teoria apresentada. Procurou-se, com estes estudos de caso, verificar quais práticas de gestão da SST são desenvolvidas nas empresas estudadas, evidenciando suas melhores iniciativas e as principais dificuldades. As empresas são denominadas neste artigo Empresa 1 e Empresa 2, sendo ambas fabricantes de baterias automotivas e localizadas na região centro-oeste do Estado de São Paulo.

A empresa 1 é certificada segundo as normas ISO 9001 (Sistema de Gestão da Qualidade) e ISO 14001 (Sistema de Gestão Ambiental), além de estar em processo de implantação da TS 16949 (Especificação Automotiva). Também pretende implantar a OHSAS 18001 (Sistema de Gestão da Segurança e Saúde no Trabalho) em curto prazo.

Seu SGSST baseia-se, quase que exclusivamente, em normas regulamentadoras instituídas pelo Ministério do Trabalho Brasileiro e nos demais requisitos legais do setor de manufatura de baterias automotivas. A sintese das suas principais características da gestão da SST está apresentada no Quadro 3.

De um modo geral, observa-se na Empresa 1 algum investimento, porém longe do mínimo necessário, em melhorias na SST e o início de um movimento para envolvimento do RH nas questões de segurança. Destaca-se o considerável esforço dos técnicos de segurança no desempenho de suas funções.

Uma das grandes reclamações destes técnicos é o não atendimento por parte de alguns colaboradores das regras de segurança estabelecidas. Esta resistência, na maioria das vezes, tem início na média gerência, o que acaba gerando conflitos com os demais colaboradores, que também não se acham obrigados a segui-las. A maioria dos gerentes que apresentam resistência às mudanças é antigo funcionário.

0 trabalho dos técnicos de segurança é desenvolvido individualmente com cada colaborador, de acordo com o nível de aceitação das normas e dos procedimentos relacionados à segurança, procurando sempre elaborar um programa personalizado de trabalho para incutir a cultura de segurança nos mais resistentes.

A empresa possui 417 colaboradores e grau de risco 4 em função de sua classificação como atividade de fabricação de baterias e acumuladores 
Quadro 3. Principais práticas de segurança e de saúde do trabalho desenvolvidas na Empresa 1.

\begin{tabular}{|c|c|}
\hline & Empresa 1 \\
\hline $\begin{array}{l}\text { Comprometimento } \\
\text { da direção }\end{array}$ & $\begin{array}{l}\text { A Direção demonstra estar razoavelmente consciente da importância da SST e vem, dentro do possível, } \\
\text { constantemente investindo na adequação do ambiente às condições seguras de trabalho. }\end{array}$ \\
\hline $\begin{array}{c}\text { Programas de } \\
\text { segurança e saúde } \\
\text { no trabalho }\end{array}$ & $\begin{array}{l}\text { Possui implantado um Programa de Prevenção de Riscos Ambientais (PPRA) e um Programa de } \\
\text { Controle Médico de Saúde Ocupacional (PCMSO). O mapa de riscos é elaborado pelos representantes } \\
\text { da Comissão Interna de Prevenção de Acidentes (CIPA) sob supervisão dos técnicos de segurança } \\
\text { do trabalho e tem como objetivo fazer um levantamento das áreas de risco e sua gravidade para as } \\
\text { atividades desenvolvidas; } \\
\text { A empresa possui em suas instalações Equipamentos de Proteção Coletiva (EPCs) e exige que seus } \\
\text { colaboradores usem Equipamentos de Proteção lndividual (EPls) em áreas onde as atividades executadas } \\
\text { geram riscos; } \\
\text { O Serviço Especializado em Engenharia de Segurança e em Medicina do Trabalho (SESMT) possui os } \\
\text { seguintes membros: } 01 \text { engenheiro de segurança do trabalho, } 01 \text { médico do trabalho e 03 técnicos } \\
\text { de segurança. As principais atividades por eles executadas são: treinamentos relativos à prevenção } \\
\text { de acidentes e implantação e acompanhamento dos programas de prevenção de acidentes e doenças } \\
\text { ocupacionais. }\end{array}$ \\
\hline $\begin{array}{l}\text { Comunicação } \\
\text { interna }\end{array}$ & $\begin{array}{l}\text { É realizado um Diálogo Semanal de Segurança (DSS), onde são relatados aos trabalhadores os acidentes } \\
\text { ocorridos na semana anterior e as ações corretivas e preventivas tomadas pela empresa para evitar sua } \\
\text { recorrência. Neste DSS, além de difundir informações relativas à segurança, a empresa também procura } \\
\text { estimular a participação dos trabalhadores na sugestão de melhorias para a prevenção de acidentes; } \\
\text { A organização investe pouco em ferramentas de comunicação interna, como painéis, banners, entre } \\
\text { outros, de forma que muitos funcionários desconhecem os novos programas desenvolvidos, ocasionando } \\
\text { baixo índice de envolvimento e resistência às mudanças propostas. }\end{array}$ \\
\hline $\begin{array}{l}\text { Programa de } \\
\text { integração } \\
\text { de novos } \\
\text { funcionários }\end{array}$ & $\begin{array}{l}\text { Mantém um programa de integração com os novos funcionários, em que são dadas orientações sobre } \\
\text { medidas de prevenção de acidentes e doenças ocupacionais. Este novo colaborador é acompanhado } \\
\text { durante os primeiros seis meses de trabalho com maior proximidade e rigidez, havendo uma avaliação } \\
\text { intensa do seu comportamento em relação às normas e procedimentos de segurança e, quando } \\
\text { necessário, os técnicos de segurança do trabalho intervêm pontualmente; } \\
\text { Um levantamento realizado pela empresa no ano de } 2006 \text { constatou que em torno de } 44 \% \text { dos } \\
\text { acidentes ocorridos envolveram colaboradores contratados a menos de um ano. }\end{array}$ \\
\hline $\begin{array}{l}\text { Medidas } \\
\text { preventivas }\end{array}$ & $\begin{array}{l}\text { Para que os funcionários não sofram danos, a empresa exige que seus colaboradores usem EPls tais } \\
\text { como protetor auditivo, óculos de segurança, respiradores semifaciais, luvas, botas de PVC e botinas } \\
\text { de segurança com bicos de aço; } \\
\text { A empresa está substituindo as botinas de segurança com bicos de aço por botinas que protegem } \\
\text { também o metatarso interno. Este é um dos exemplos do investimento na melhoria de instrumentos } \\
\text { de prevenção. }\end{array}$ \\
\hline $\begin{array}{l}\text { Recursos } \\
\text { humanos }\end{array}$ & $\begin{array}{l}\text { O baixo envolvimento da área de Recursos Humanos nos treinamentos realizados pela organização é } \\
\text { um obstáculo para o alcance de melhores resultados na conscientização dos envolvidos no processo de } \\
\text { implantação/gerenciamento do SGSST. A participação do setor é muito tímida, sendo que os maiores } \\
\text { esforços ainda se concentram nas mãos dos técnicos de segurança do trabalho; } \\
\text { A área de Recursos Humanos está iniciando um programa de desenvolvimento de lideranças, onde, além } \\
\text { da média gerência, outros colaboradores serão treinados para entenderem e desenvolverem trabalhos } \\
\text { voltados à visão estratégica da organização, sendo a melhoria do SGSST um dos principais objetivos. }\end{array}$ \\
\hline
\end{tabular}

para veículos, e, de acordo com a NR 4, tem o SESMT corretamente dimensionado para sua estrutura e atividades.

Os resultados SGSST não estão vinculados a nenhum sistema de remuneração ou qualquer outro incentivo, porém existem estudos para que isto venha a acontecer no futuro.

A Empresa 2 é certificada segundo a norma ISO 9001 e está em processo de implantação da norma ISO 14001. Ela também pretende futuramente implantar a OHSAS 18001.

0 sistema de segurança desta organização também se baseia majoritariamente em normas regulamentadoras e em outros requisitos legais pertinentes ao setor de baterias automotivas, porém verificaram-se alguns elementos de gestão que vão um pouco além do que exigem estas legislações. A síntese das suas principais características da gestão da SST está apresentada no Quadro 4.

Na Empresa 2 percebe-se maior eficiência no desenvolvimento, execução e acompanhamento das medidas de SST. A maioria das atividades é executada pelos técnicos de segurança do trabalho, que possuem maior experiência na área. Contudo, há um grande esforço da área de recursos humanos em se envolver nestas atividades, principalmente no que diz respeito à treinamento de funcionários. 
Quadro 4. Principais práticas de segurança e saúde do trabalho desenvolvidas na Empresa 2.

\begin{tabular}{|c|c|}
\hline & Empresa 2 \\
\hline $\begin{array}{l}\text { Comprometimento } \\
\text { da direção }\end{array}$ & $\begin{array}{l}\text { Segundo os técnicos de segurança, a direção possui total consciência da importância do seu papel } \\
\text { no incentivo às iniciativas de SST e efetivamente dá o aporte humano e financeiro necessário para a } \\
\text { melhoria das atividades. }\end{array}$ \\
\hline $\begin{array}{l}\text { Programas de } \\
\text { segurança e saúde } \\
\text { no trabalho }\end{array}$ & $\begin{array}{l}\text { Possui implantado um PPRA e um PCMSO com a finalidade de preservar a saúde e a integridade } \\
\text { física dos colaboradores, bem como auxiliar no desenvolvimento de medidas de melhoria contínua do } \\
\text { ambiente de trabalho. } 0 \text { mapa de riscos setorial é desenvolvido pela CIPA e disponibilizado em locais- } \\
\text { chave em toda empresa (fácil visualização e leitura); } \\
\text { A empresa utiliza em suas instalações os seguintes EPls baseados na NR 6: respirador com filtro P3, } \\
\text { protetor auditivo, botinas de segurança com bicos de aço, luvas de segurança, capuz, máscara de solda, } \\
\text { bota de borracha, óculos de segurança, capacete e cinto de segurança; } \\
\text { É também feito um mapeamento das partes do corpo atingidas e mais prejudicadas durante a execução } \\
\text { das tarefas. É importante ressaltar que primeiramente se busca evitar os acidentes contra a cabeça e } \\
\text { depois as outras partes do corpo, garantindo um equipamento mais específico para cada atividade; } \\
0 \text { SESMT é composto por } 03 \text { técnicos de segurança, } 01 \text { médico do trabalho e } 01 \text { auxiliar de } \\
\text { enfermagem. }\end{array}$ \\
\hline $\begin{array}{c}\text { Comunicação } \\
\text { interna }\end{array}$ & $\begin{array}{l}\text { O departamento de segurança, os membros da CIPA, os supervisores e os encarregados fazem inspeções } \\
\text { rotineiras com relação às condições inseguras e monitoram as atividades dos funcionários. Se não } \\
\text { houver o cumprimento das normas de segurança estabelecidas pela empresa, o infrator é orientado } \\
\text { sobre os riscos e as consequências para a sua própria saúde e, se houver reincidência, são aplicadas } \\
\text { medidas administrativas; } \\
\text { A empresa disponibiliza um documento chamado formulário de solicitação de serviços para solicitar } \\
\text { e priorizar a manutenção e/ou adequação do ambiente físico de trabalho às condições adequadas à } \\
\text { saúde e segurança dos colaboradores. Neste documento é possivel identificar que a solicitação está } \\
\text { relacionada com questões de segurança do trabalho e, neste caso, passa a ter prioridade sobre as } \\
\text { demais solicitações; } \\
\text { Esta organização também investe pouco em ferramentas de comunicação interna, principalmente pelo } \\
\text { fato dos seus técnicos acreditarem que o diálogo produz um efeito maior com relação aos funcionários } \\
\text { do que pela divulgação visual. }\end{array}$ \\
\hline $\begin{array}{l}\text { Programa de } \\
\text { integração } \\
\text { de novos } \\
\text { funcionários }\end{array}$ & $\begin{array}{l}\text { Quando um funcionário é admitido passa por um processo de integração que envolve o departamento } \\
\text { médico, o Serviço Social, Departamento de Recursos Humanos (DRH) e Departamento de Segurança } \\
\text { e Nutrição. Cada setor aborda os assuntos relacionados à sua área. No caso específico do setor de } \\
\text { segurança, são tratados os riscos operacionais, planejamento de serviços, medidas de prevenção de } \\
\text { acidentes, conceitos de acidentes do trabalho, direito de recusa quando não houver condições técnicas, } \\
\text { físicas ou emocionais para o trabalho, equipamentos de proteção coletiva, equipamentos de proteção } \\
\text { individual, meio ambiente e normas de segurança; } \\
\text { Também são realizados treinamentos específicos para SST com planejamento anual, de acordo com } \\
\text { as necessidades percebidas durante as inspeções de segurança e acompanhamentos das atividades de } \\
\text { rotina. }\end{array}$ \\
\hline $\begin{array}{l}\text { Medidas } \\
\text { preventivas }\end{array}$ & $\begin{array}{l}\text { A empresa possui, para cada funcionário, um documento chamado histórico de segurança, onde são } \\
\text { relatados os acidentes em que o funcionário se envolveu direta ou indiretamente (arquivo de acidente), } \\
\text { quais os cursos foram feitos na admissão e durante sua vida na empresa (arquivo de treinamento) e as } \\
\text { advertências de cada trabalhador (arquivo de advertência). Este histórico facilita a tomada de decisão } \\
\text { e o planejamento de treinamentos relativos à SST. }\end{array}$ \\
\hline $\begin{array}{l}\text { Recursos } \\
\text { humanos }\end{array}$ & $\begin{array}{l}\text { O DRH participa de grande parte das ações realizadas pelo Departamento de Segurança, principalmente } \\
\text { no que diz respeito a treinamento de funcionários, transferências para outro setor ou função e } \\
\text { orientações de segurança. }\end{array}$ \\
\hline
\end{tabular}

Esta empresa possui 362 colaboradores, é classificada, de acordo com a NR 4, como grau de risco 4 (fabricação de baterias e acumuladores para veículos) e tem o SESMT incorretamente dimensionado para sua estrutura e atividades.

A organização possui operadores treinados, equipamentos em bom estado de conservação, procedimentos de manutenção corretiva, preventiva, preditiva, além de um check list diário visando à segurança e saúde dos trabalhadores.
Cabe salientar que os resultados da SST na Empresa 2, mesmo apresentando o SESMT subdimensionado, são melhores que os da Empresa 1. Isto se deve, principalmente, ao comprometimento e apoio da Alta Direção e a parceria estabelecida com a área de Recursos Humanos. Estas iniciativas têm feito a diferença no desempenho do sistema de segurança.

As principais dificuldades enfrentadas pelas Empresas 1 e 2 na gestão dos seus SGSST estão apresentadas no Quadro 5. 
Ressalta-se o grande receio das empresas estudadas em liberar/divulgar suas informações operacionais relativas à segurança e saúde do trabalho. Esta postura, infelizmente, não permitiu que os pesquisadores tivessem acesso a algumas informações que melhor ilustrariam e permitiriam entender ainda mais a dinâmica destas funções no ambiente organizacional.

Alguns dados puderam ser verificados e foram apresentados neste trabalho com permissão das empresas, tais como o dimensionamento da SESMT e algumas poucas outras informações provenientes de pesquisas realizadas pelas próprias instituições estudadas, que por este motivo não se pôde confirmar o rigor metodológico de sua realização. Não se trata da situação ideal almejada pelos pesquisadores, mas foi aquela com que se teve que trabalhar e, portanto, equacionar.

\section{Boas práticas para gestão de sistemas de SST}

Com base no referencial teórico e nos estudos de caso realizados, apresentam-se, a seguir, algumas boas práticas para a gestão de sistemas de segurança e saúde no trabalho:

- Comprometimento da alta direção: quando os funcionários começam a acreditar no real comprometimento da Direção para com o SGSST, eles sentem-se mais dispostos a participar das iniciativas propostas pela organização e contribuem com a proposição de sugestões para a melhoria do ambiente de trabalho, execução das medidas estabelecidas e auxílio na conscientização dos demais colaboradores;
- Minimização da resistência às mudanças: fenômenos como conflitos, incertezas, medo do desconhecido, falta de informação e sensações de perda de poder podem gerar resistência às mudanças propostas e interferir negativamente na implantação de SGSSTs. A resistência pode ser minimizada por meio de ações diversas: incentivos a maior participação dos colaboradores no sistema, valorização de opiniões, capacitação e adequada disponibilização de informações e recursos;

- Identificar aspectos da cultura da organização que podem contribuir ou prejudicar o SGSST: fazer uma análise do perfil dos colaboradores e sua relação com a organização para que se consiga identificar as principais resistências que podem surgir durante a gestão de sistemas de SST tentando saná-las previamente, de maneira a não causar perturbações desnecessárias;

- Capacitação técnica e gerencial dos profissionais responsáveis pela SST: os técnicos de segurança do trabalho devem possuir habilidades tanto técnicas como gerenciais e ter consciência de que para trabalhar em equipe e gerenciar pessoas é necessário mostrar os benefícios individuais e coletivos da prevenção de acidentes;

- Investir em comunicação interna: a empresa deve utilizar os meios e técnicas de comunicação compatíveis com o nível de cultura de seus funcionários a fim de informar os objetivos da empresa e as oportunidades que novos procedimentos SST ou um novo sistema de gestão estruturado da segurança pode proporcionar;

- Desenvolver um mapa setorial de riscos: este mapa de riscos tende a ser melhor aceito pelos colaboradores por resultar em maior conhecimento e proximidade entre o trabalhador e o local com possível risco de gerar acidente. Desta forma, o

Quadro 5. Principais dificuldades encontradas no gerenciamento do SGSST nas empresas estudadas.

\begin{tabular}{|l|l|}
\hline \multicolumn{1}{|c|}{ Empresa 1 } & \multicolumn{1}{c|}{ Empresa 2 } \\
\hline Resistência às mudanças; & Dificuldade na elaboração de procedimentos e instruções; \\
\hline Baixo índice de escolaridade dos funcionários; & $\begin{array}{l}\text { Ausência de indicadores de desempenho em segurança e } \\
\text { saúde no trabalho; }\end{array}$ \\
\hline Dificuldade na elaboração de procedimentos e instruções; & Rotatividade de funcionários terceirizados; \\
\hline Falhas na comunicação interna; & Baixo índice de conscientização dos funcionários; \\
\hline Baixo envolvimento dos demais setores da organização; & $\begin{array}{l}\text { Não estabelecer a segurança e saúde como um dos objetivos } \\
\text { estratégicos da empresa; }\end{array}$ \\
\hline $\begin{array}{l}\text { Ausência de indicadores de desempenho em segurança e } \\
\text { saúde no trabalho; }\end{array}$ & $\begin{array}{l}\text { Apesar de algum apoio, ainda faltam recursos financeiros } \\
\text { para o setor; }\end{array}$ \\
\hline $\begin{array}{l}\text { Entendimento por parte de todos de que o Departamento } \\
\text { de Segurança é o único responsável pelos resultados do } \\
\text { sistema de gestão da segurança e saúde no trabalho; }\end{array}$ & $\begin{array}{l}\text { Somente os técnicos de segurança do trabalho acreditam } \\
\text { na necessidade de elaboração de projetos de mudança e } \\
\text { melhoria de desempenho na área de SST; }\end{array}$ \\
\hline Falta de comprometimento da média gerência; & Baixo índice de escolaridade dos funcionários. \\
\hline Baixo índice de conscientização dos funcionários; & $\begin{array}{l}\text { Não estabelecimento da segurança e saúde como um dos } \\
\text { objetivos estratégicos da empresa; }\end{array}$ \\
\hline $\begin{array}{l}\text { Baixo envolvimento da Área de Recursos Humanos nos } \\
\text { treinamentos. }\end{array}$ & \\
\hline
\end{tabular}


mapa se torna mais específico e de fácil leitura, ainda mais quando é confeccionado com a participação da mão-de-obra envolvida;

- Investir em treinamentos técnicos e comportamentais: o treinamento deve ser entendido como um meio eficaz para desenvolver competências específicas nos colaboradores e torná-los mais produtivos e criativos. Para isto, é necessário que sejam planejados de acordo com as necessidades identificadas no SGSST e de acordo com os requisitos exigidos em cada função;

- Parceria com a área de recursos humanos: o envolvimento da área de recursos humanos em todos os processos de mudança, sobretudo naqueles relacionados à SST, é importante para que sejam identificadas as necessidades de treinamento relacionadas ao desenvolvimento dos funcionários, bem como a utilização de técnicas apropriadas para mitigação dos focos de resistência, possibilitando melhor entendimento e real comprometimento dos colaboradores com as mudanças propostas; e

- Definir indicadores de desempenho em SST e retroalimentar o sistema: a empresa deve definir, implementar e monitorar indicadores de desempenho específicos para as atividades relacionadas à SST. Eles têm como objetivo permitir que a alta direção, os gerentes e os demais colaboradores visualizem o status do desempenho do SGSST, permitindo, a partir disto, a realização de uma autoavaliação da performance e o estabelecimento de planos de ação para eventuais correções dos objetivos e metas estabelecidos.

\section{Conclusão}

A partir deste estudo foi possivel identificar e sistematizar algumas boas práticas, apresentadas de forma introdutória e resumida neste artigo, e as principais dificuldades relacionadas à segurança e saúde no trabalho em duas empresas fabricantes de baterias automotivas.

Após a análise dos dados, verificou-se que as empresas têm como objetivo apenas atender as normas regulamentadoras e outros requisitos legais pertinentes ao setor de baterias automotivas, indo muito pouco além das exigências legais. Aimplantação de SGSSTs certificáveis, como por exemplo a OHSAS 18001, ainda é um objetivo futuro.

Esta pesquisa evidenciou que o apoio da alta direção, da área de Recursos Humanos e a participação ativa dos colaboradores na gestão da SST é determinante para o sucesso do referido sistema, corroborando com o que a teoria preceitua.

Dentre as dificuldades verificadas nos estudos de caso, podem-se destacar: falha na comunicação entre os níveis hierárquicos, baixo grau de participação dos trabalhadores no sistema, inadequado planejamento das ações, insegurança dos colaboradores, ausência de indicadores para a medição de desempenho da SST e não estabelecimento da segurança como um dos objetivos estratégicos da empresa.

Os resultados da pesquisa (sistematização de boas práticas, ou seja, a proposição de recomendações para gestão de SST em empresas de baterias automotivas), conforme preceitua Yin (2003), foram validados nesta pesquisa com base na referencial teórico e nos dois estudos de caso realizados.

Acredita-se, portanto, que o objetivo deste trabalho foi alcançado, pois por meio dos estudos de caso realizados e da síntese da teoria apresentada foi possível identificar as boas práticas de segurança e saúde no trabalho desenvolvidas pelas empresas e as principais dificuldades encontradas no seu gerenciamento.

Como limitação principal deste trabalho, ressalta-se a impossibilidade de generalização estatística dos seus resultados.

\section{Referências}

ABUDAYYEH, O. et al. An investigation of management's commitment to construction safety. International Journal of Project Management, v. 24, n. 2, p. 167-174, 2006.

AGgELOGIANNOPOULOS, D.; DROSINOS, E. H.; ATHANASOPOULOS, P. Implementation of a quality management system (QMS) according to the ISO 9000 family in a Greek small-sized winery: a case study. Food Control, v. 18, n. 9, p. 1077-1085, 2007.

ANHALON, R.; ZOQUI, E. J.; PINTO, J. S. Principais dificuldades vivenciadas na implementação de um sistema de gestão da qualidade adaptado em empresas incubadas na região de Jundiaí. In: ENCONTRO NACIONAL DE ENGENHARIA DE PRODUÇÃo, 2005, Porto Alegre. Anais... Porto Alegre: ABEPRO, 2005.

BARBOSA FILHO, A. N. Segurança do trabalho e gestão ambiental. São Paulo: Atlas, 2001.

BEER, M.; NOHRIA, N. Desenvolvendo o código da mudança. HSM Management, v. 25, p. 126-132, 2001.

CENTRO DA QUALIDADE, SEGURANÇA E PRODUTIVIDADE QSP. São Paulo, 2010. Disponivel em: <http://www.qsp. org.br/>. Acesso em: 02 jan. 2009.

CHOUDHRY, R. M.; FANG, D.; MOHAMED, S. The nature of safety culture: a survey of the state-of-the-art. Safety Science, v. 45, n. 10, p. 993-1012, 2007.

HASLE, P.; JENSEN, P. L. Changing the internal health and safety organization through organizational learning and change management. human factors and ergonomics in manufacturing. InterScience, v. 16, n. 3, p. 269-284, 2006.

KOUFTEROS, X. A.; VONDEREMBSE, M. A.; DOLL, W. J. Integrated product development practices and competitive capabilities: the effects of uncertainty, equivocality, and platform strategy. Journal of Operations Management, v. 20, n. 4, p. 331-355, 2002. 
LANGFORD, D.; ROWLINSON, S.; SAWACHA, E. Safety behavior and safety management: its infuence on the attitudes in the UK construction industry. Engineering Construction and Architectural Management Journal, v. 7, n. 2, p. 133-140, 2000.

LIN, J.; MILLS, A. Measuring the occupational health and safety performance of construction companies in Australia. Facilities, v. 19, n. 3-4, p. 131-138, 2001.

MILAN, G. S.; PRETTO, M. R.; PIGOZZl, P. R. A relação entre a gestão da qualidade e a cultura organizacional: um estudo-de-caso ambientado em uma fábrica de embalagens de papelão. In: ENCONTRO NACIONAL DE ENGENHARIA DE PRODUÇÃO, 2005, Porto Alegre. Anais... Porto Alegre: ABEPRO, 2005.

MOHAMED, S. Safety climate in construction site environments. Engineering Construction and Architectural Management Journal, v. 128, n. 5, p. 375-84, 2002.

OCCUPATIONAL HEALTH AND SAFETY MANAGEMENT SYSTEMS - OHSAS. OHSAS 18001: requirements. London: British Standards Instituition, 2007.

QUELHAS, 0. L. G.; ALVES, M. S.; FILARDO, P. S. As práticas da gestão da segurança em obras de pequeno porte: integração com os conceitos de sustentabilidade. Revista Produção On Line, v. 4. n. 2, 2003. Disponível em: http:// producaoonline.org.br/index.php/rpo/article/view/309. Acesso em: 20 jan. 2009.

RAYMOND, L.; BERGERON, F. Project management information systems: an empirical study of their impact on project managers and project success. International Journal of Project Management, v. 26, n. 2, p. 213-220, 2008.
ROBSON, L. S. et al. The effectiveness of occupational health and safety management system interventions: a systematic review. Safety Science, v. 45, n. 3, p. 329-353, 2007.

SALOMONE, R. Integrated management systems: experiences in Italian organizations. Journal of Clearner Production, v. 16, n. 16, p. 1786-1806, 2008.

SANTOS, G. T.; ROSSI, G.; JARDILINO, J. R. L. Orientações metodológicas para elaboração de trabalhos acadêmicos. 2 ed. São Paulo: Gion Editora, 2000.

$\mathrm{SHI}$, H. et al. Barriers to the implementation of cleaner production in Chinese SMEs: government, industry and expert stakeholders' perspectives. Journal of Cleaner Production, v. 16, n. 7, p. 842-852, 2008.

TRIVELATO, G. C. Sistema de gestão da segurança e saúde no trabalho: fundamentos e alternativas. Belo Horizonte, MG, 2002. Apresentação feita no Seminário Nacional sobre gestão da segurança e saúde no trabalho. Brasília, 2009. Disponível em: <http://www.fundacentro.gov.br/ CTN/sistemas_gestao_saude_trabalho.pdf $>$. Acesso em: 01 jan. 2009.

YIN, R. K. Case study research: design and methods. 3. ed. London: Sage Publications, 2003.

\section{Agradecimentos}

Agradecemos à FAPESP pela bolsa concedida a um dos autores.

\title{
Management of occupational health and safety in automotive battery companies: a study to identify best practices
}

\begin{abstract}
Occupational Health and Safety management $(\mathrm{OSH})$ reduces the risk of accidents, promotes worker health and satisfaction and improves operational results and the image of organizations, especially those in the industrial sector. The main objective of this paper is to identify best practices and the main difficulties related to OSH management at automobile battery manufacturers in the midwest of the State of São Paulo, using the double case study method. Data was collected using on-site observation, document analysis and semi-structured interviews with managers and collaborators. The study revealed that support by top management, Human Resources and the active participation of collaborators are determining factors for the system's success and that the main difficulties in its management are failures in communication, nonexistence of $\mathrm{OSH}$ indicators and the lack of a strategic vision for safety.
\end{abstract}

Keywords

Safety and occupational health. Management systems. Automotive batteries. Management practices. 